\title{
Extension of Calcifying Epithelial Odontogenic Tumor to the Maxillary Sinus: A Case Report
}

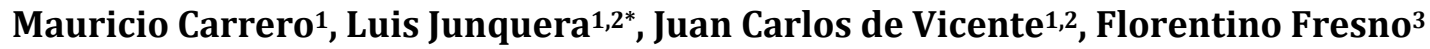 \\ ${ }^{1}$ Department of Oral and Maxillofacial Surgery, Central University Hospital, Oviedo, Spain \\ ${ }^{2}$ Department of Oral and Maxillofacial Surgery, University of Oviedo Dental School, Oviedo, Spain \\ ${ }^{3}$ Department of Pathologic Anatomy, Central University Hospital, Oviedo, Spain \\ Email: ${ }^{\text {junquera@uniovi.es }}$
}

Received 8 April 2014; revised 12 May 2014; accepted 20 May 2014

Copyright (C) 2014 by authors and Scientific Research Publishing Inc.

This work is licensed under the Creative Commons Attribution International License (CC BY).

http://creativecommons.org/licenses/by/4.0/

c) (i) Open Access

\begin{abstract}
The calcifying epithelial odontogenic tumor (CEOT) is a rare and benign odontogenic epithelial neoplasm. This tumor accounts for less than $1 \%$ of all odontogenic tumors. It normally affects patients between $\mathbf{3 0}$ and $\mathbf{5 0}$ years old, and it is typically located in the posterior region of the mandible. Involvement of the maxillary sinus has previously been published only in six cases. This report presents a single case of CEOT that invades the maxillary sinus in a 69-year-old male. We performed a left partial maxillectomy and immediate reconstruction of the defect with a temporalis muscle flap. A comprehensive immunohistochemical study was reported. No recurrences have been found after 8 years of follow-up.
\end{abstract}

\section{Keywords}

Pindborg Tumor, Calcifying Epithelial Odontogenic Tumor, Maxillary Sinus

\section{Introduction}

The calcifying epithelial odontogenic tumor (CEOT) was first described by the Danish pathologist Jens Jørgen Pindborg in 1955 [1]. It is considered a rare and benign odontogenic neoplasm, and its origin is exclusively epithelial [2]. Its etiology is unclear, but three theories are accepted: remanent epithelial cells in the intermediate layer of the enamel organ, a disordered immune response to the intermediate layer cells or epithelial remnants of the primitive dental lamina [2] [3].

${ }^{*}$ Corresponding author.

How to cite this paper: Carrero, M., et al. (2014) Extension of Calcifying Epithelial Odontogenic Tumor to the Maxillary Sinus: A Case Report. Open Journal of Stomatology, 4, 280-284. http://dx.doi.org/10.4236/ojst.2014.45039 
The CEOT represents about $1 \%$ of all odontogenic tumors [1] [4]-[6], with a peak prevalence in the third and fifth decades [2] [7], but some unusual cases have been reported in the first decade and beyond the seventh decade of life [6]. Most authors have found no difference by gender [2] [3] [5] [7], however, Ostern et al. [6] in a recent study, reported that odontogenic tumors seem to show a geographic variation whenever the CEOT's show a male-female ratio 1.7:1.

Two clinico-topographic variants have been reported in the English literature, the intraosseous and extraosseous, with an incidence of $94 \%$ and $6 \%$ respectively [8] [9]. The intraosseous or central variant has a mandible-maxilla ratio 3:1 [2] [3] [6], being the molar region 3 times more common than the premolar [2] [3]. This variant is associated with unerupted teeth in $52 \%-54 \%$ of the cases [3] [5]. The peripheral extraosseous variant is most frequently seen in the gingiva and the anterior region of mandible [1] [8], being this variant less aggressive [5]. There have been less than 40 documented cases of CEOTs that were immunohistochemically investigated with a variety of antibodies [10].

Here, we report a case of an elderly patient affected by a CEOT located in the posterior maxilla with maxillary sinus extension. A comprehensive immunohistochemical study was discussed and a review of the literature on the main features of this neoplasm was done.

\section{Case Report}

A 69-year-old male presents as an outpatient in June 2003, with a painless swelling and slow maxillary growth with an uncertain time of disease evolution. He refers a medical history of high blood pressure and dyslipidemia. A month before, he had his upper left first molar removed by his dentist. The clinical examination shows a painless swelling of about $4 \times 3 \mathrm{~cm}$ which affected the entire left maxillary molar region and it was fluctuating on palpation.

The orthopantomogram revealed the existence of a radiolucency consistent with an odontogenic cyst, and unerupted upper third molars (Figure 1). Computed tomography (CT) scan showed an osteolytic image about $4 \mathrm{~cm}$ in diameter with destruction of the anterior and lateral walls of the left maxillary sinus and part of the zygoma, with an almost complete disappearance of the ipsilateral maxillary alveolar bone (Figure 2). The radiologist's report concluded that it could be a radicular cyst since the root of the second premolar was within the lesion.

Biopsy of the lesion showed the existence of epithelial proliferation of polygonal elements with prominent intercellular bridges, enlarged and pleomorphic nucleus with a low proliferative tendency and the presence of homogenous eosinophilic "amyloid like" material interspersed between the cells (Figure 3). The histopathologic diagnosis was calcifying epithelial odontogenic tumor.

One month after the biopsy, the patient underwent surgery with general anesthesia; the tumor was removed with margins of at least $1.5 \mathrm{~cm}$ and a reconstruction of the defect through a left temporal flap was done. The Pathological report of the specimen extracted confirmed the result of the biopsy. Representive tissue sections con-

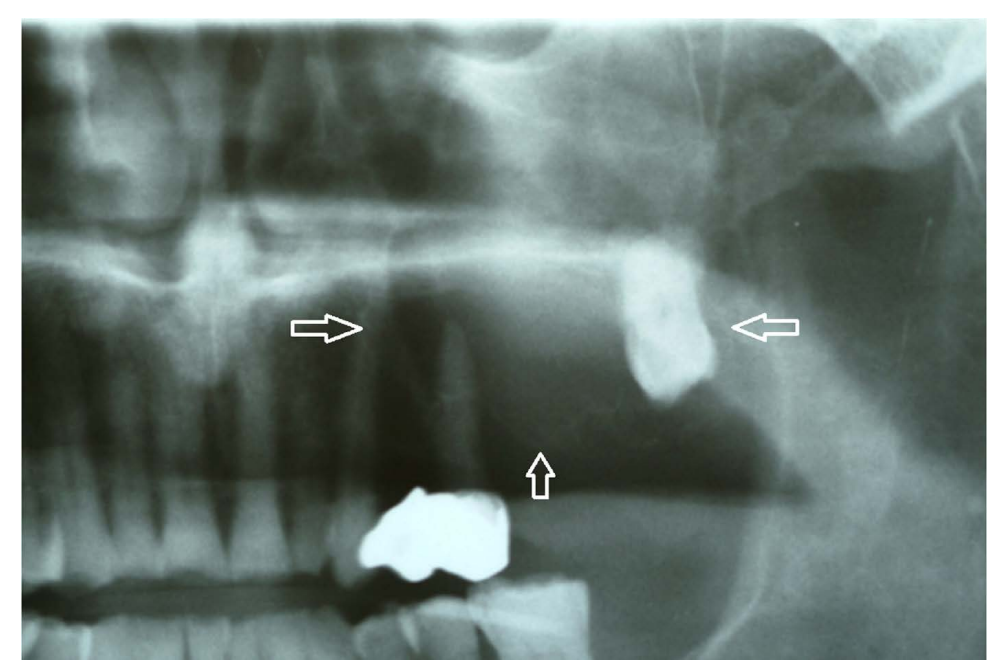

Figure 1. Orthopantomogram showing osteolytic imagen. The root of the second premolar was within the lesion. 


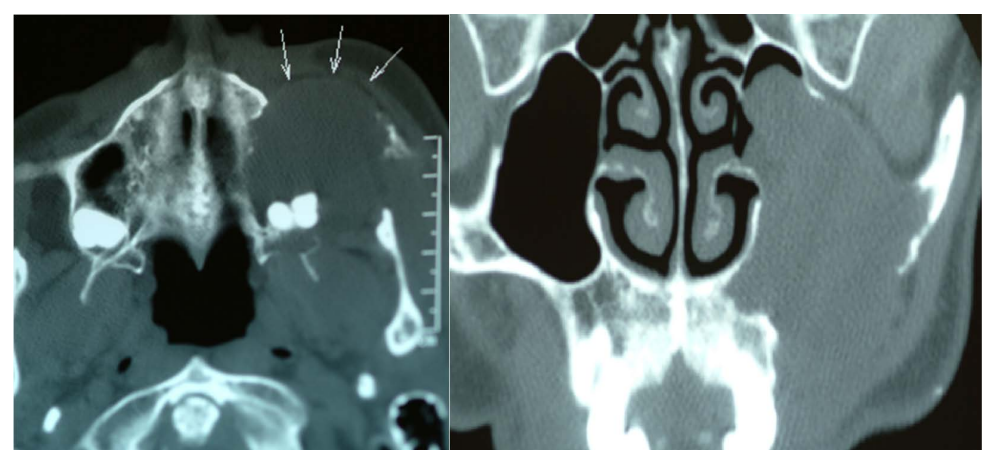

Figure 2. Computer tomographic scan showing destruction of the anterior and lateral walls of the left maxillary sinus and zygoma.

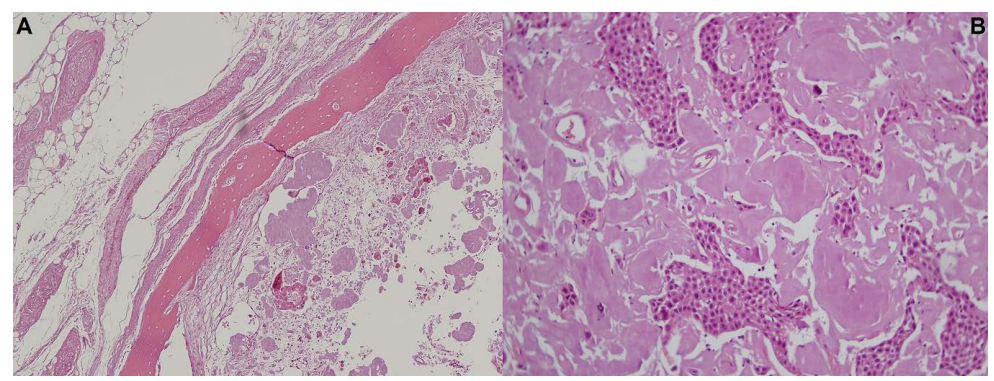

Figure 3. Hematoxylin-eosin staining: (A) 100× magnification. (B) 400× magnification.

taining the areas of CEOT were inmunohistochemically stained for Ki-67 (Figure 4). Tumor proliferative activity determined by the Ki-67 labeling index (percentage) was assessed by counting 1000 tumor cells per tissue section. Tumor proliferation rate as defined by Ki-67 labeling index was lower than $10 \%$. The neoplastic cells showed positive immunoreactivity to odontogenic epithelium specific cytokeratin (CK19). No recurrences have been found after 8 years of follow-up.

\section{Discussion}

The CEOT has been described as a typically benign tumor [2], eight cases have been reported in the English literature with metastases and aggressive infiltration [9]. The involvement of the maxillary sinus tumor has previously been published only in six cases, and it is extremely rare [4] [11]-[15]. We report a case of CEOT that invades the maxillary sinus in a 69-year-old male.

Most of the CEOTs are indolent and are discovered by a routine radiological examination. Frequently clinical findings are a slow-growing painless swelling, expansible, with very thin cortical walls described as "egg-shell", and $60 \%$ of cases located in mandible posterior body to ascending ramus region [2]. However, if the lesion is located in the maxilla, the most common symptom is nasal obstruction [15], and in advanced cases the displacement of the ocular globe has been reported [4].

Three stages of evolution for this entity are radiographically recognized. The first one shows a radiolucent image, similar to a dentigerous cyst, especially if there is an unerupted tooth involved [5]. In a second stage, intratumoral calcifications can occur and are not pathognomonic [5], showing a mixed pattern of "wind driven snow" [2] [4]. Finally, bone destruction and tumor calcification show a multilobulated pattern of small and large spaces known as "honeycomb" and "soap bubble", respectively [2]. If the CEOT is located in the posterior mandible segments, misinterpretation with ameloblastomas is very likely [7].

The histologic pattern is typical and well defined [7]. Characteristically there are large polygonal epithelial cells with well-defined borders, often joined by prominent intercellular bridges, hyperchromatic nucleous located between a homogenous eosinophilic "amyloid-like" material, which gradually becomes calcified, forming the "Liesengang rings" [5] [7], which are considered pathognomonic for this tumor [1]. The eosinophilic material in our case has an apple-green birefringence under polarized light after staining with Congo red. The neoplasm- 


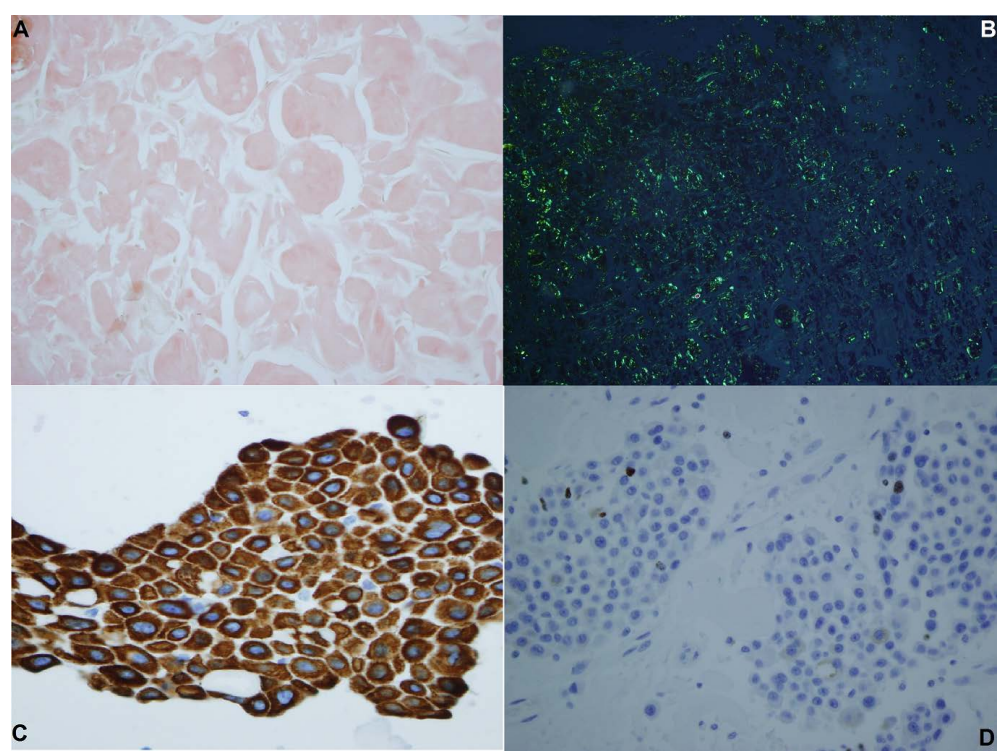

Figure 4. Immunohistochemical study: (A) Congo red stain (100× magnification); (B) Congo red stain under polarized light source showing apple-green color birefringence of amyloid deposited in fibrous connective tissue stroma (100× magnification); (C) Cytokeratin 19 (400× magnification); (D) Ki-67 staining (400× magnification).

tic cells of the present study showed positive immunoreactivity to CK19. These results indicate the epithelial nature of the CEOT-neoplastic cells [10]. Additionally, the morphology of these neoplastic cells suggests that they are of squamous epithelial origin [10].

However, others variants of not-calcifying CEOT have been recently described, CEOT with Langerhans cells and CEOT with cement-like and bone-like material, they are known to be less aggressive. Treatment is a more conservative surgical approach [1] [9]. Other variants are CEOT associated to adenomatoid odontogenic tumor and clear cell CEOT, this one, is more aggressive with a higher rate of recurrence, so more radical surgical treatment would be indicated [9].

The differential diagnosis for CEOTs are ameloblastoma, odontogenic myxoma, ameloblastic fibroma, ameloblastic fibro-odontoma, dentigerous cyst, keratocystic odontogenic tumor, ossifying fibroma and central giant cell granuloma [2] [5].

Treatment of intraosseous CEOT is surgical, either conservative (enucleation or curettage) or more aggressive (marginal or segmental resection), but the decision must analyze many features such as size and location of the neoplasm, degree of bone destruction, histological findings, and the patient's age and overall condition [1]-[3] [5]. In general, we recommend enucleation with curettage in small mandibular lesions [3]. Resection with tumor free bone margins of at least $1 \mathrm{~cm}$ will be recommend in lesions larger than $4 \mathrm{~cm}$ [2], recurrence [5] or involvement of the maxilla, as this location shows a higher growth rate to invade vital structures [2] [3] [16]. Treatment of extraosseous CEOT is also surgical, but could be a simple local excision [2].

The intraosseous CEOT shows a recurrence rate of 14\% - 15\% [1]-[3] [5] [16], whereas extraosseous CEOT does not have any recurrence case documented [2]. Due to the wide range of intraosseous CEOT recurrence in years or decades, annual follow-up examination with radiographic survey is recommended [2].

\section{Conclusion}

This report documents a new case of CEOT localized in the left maxilla with extension to the maxillary sinus. Only six cases have been previously published. Despite the advanced age of the patient and the low rate of tumor proliferation with a low Ki-67, it may lead us to suggest that the time of disease evolution could not participate in the malignant transformation of this entity. There is no evidence of recurrences after 8 years of annual follow-up examination; this confirms the hypothesis that resection with tumor free bone margins lead to fewer recurrences. 


\section{References}

[1] Angadi, P.V. and Rekha, K. (2011) Calcifying Epithelial Odontogenic Tumor (Pindborg Tumor). Head and Neck Pathology, 5,137-139. http://dx.doi.org/10.1007/s12105-011-0250-6

[2] Goode, R.K. (2004) Calcifying Epithelial Odontogenic Tumor. Oral \& Maxillofacial Surgery Clinics of North America, 16, 323-331. http://dx.doi.org/10.1016/j.coms.2004.03.002

[3] Rapidis, A., Stavrianos, S.D., Andressakis, D., Lagogiannis, G. and Bertín, P.M. (2005) Calcifying Epithelial Odontogenic Tumor (CEOT) of the Mandible: Clinical Therapeutic Conference. Journal of Oral and Maxillofacial Surgery, 63, 1337-1347. http://dx.doi.org/10.1016/j.joms.2005.05.309

[4] Bridle, C., Visram, K., Piper, K. and Ali, N. (2006) Maxillary Calcifying Epithelial Odontogenic (Pindborg) Tumor Presenting with Abnormal Eye Signs: Case Report and Literature Review. Oral Surgery, Oral Medicine, Oral Pathology, Oral Radiology and Endodontology, 102, e12-e15. http://dx.doi.org/10.1016/j.tripleo.2005.12.019

[5] Belmonte, R., Torres, D., Mayorga, F., Garcia-Perla, A., Infante, P. and Gutierrez, J.L. (2002) Tumor Odontogénico Epitelial Calcificante (Tumor de Pindborg). Medicina Oral, 7, 309-315.

[6] Osterne, R.L., Galvão de Matos, R., Negreiros, A.P., Barroso, R. and Bitu, F. (2011) Odontogenic Tumors a 5-Year Retrospective Study in a Brazilian Population and Analysis of 3406 Cases Reported in the Literature. Oral Surgery, Oral Medicine, Oral Pathology, Oral Radiology and Endodontology, 111, 474-481. http://dx.doi.org/10.1016/j.tripleo.2010.10.018

[7] Peña-Torres, L.M., Monterrubio-Guerrero, A. and Diaz, L.A. (2010) Tumor Odontogénico Epitelial Calcificante (Tumor de Pindborg). Informe de un caso y Revisión de la Literatura. Rev Med Inst Mex Seguro Soc., 48, 205-208.

[8] Sedghizadeh, P., Wong, D., Shuler, C.F., Linz, V., Kalmar, J.R. and Allen, C.M. (2007) Multifocal Calcifying Epitelial Odontogenic Tumor . Oral Surgery, Oral Medicine, Oral Pathology, Oral Radiology and Endodontology, 104, e30-e34. http://dx.doi.org/10.1016/j.tripleo.2006.06.050

[9] Demian, N., Harris, R., Abramovitch, K., Wilson, J. and Vigneswaran, N. (2010) Malignant Transformation of Calcifying Epithelial Odontogenic Tumor Is Associated with the Loss of p53 Transcriptional Activity: A Case Report with Review of the Literature. Journal of Oral and Maxillofacial Surgery, 68, 1964-1973. http://dx.doi.org/10.1016/j.joms.2010.02.017

[10] Poomsawat, S. and Punyasingh, J. (2007) Calcifying Epithelial Odontogenic Tumor: An Immunohistochemical Case Study. Journal of Molecular Histology, 38, 103-109. http://dx.doi.org/10.1007/s10735-007-9082-9

[11] Larsen, P.O. and Poulsen, P. (1989) Pindborg Tumor in the Maxillary Sinus. An Unusual Case of Atypical Facial Pain. Ugeskrift for Lager, 151, 32.

[12] Lee, C.Y., Mohammadi, H., Mostofi, R. and Habibi, A. (1992) Calcifying Epithelial Odontogenic Tumor of the Maxillary Sinus. Journal of Oral and Maxillofacial Surgery, 50, 1326-1328. http://dx.doi.org/10.1016/0278-2391(92)90237-T

[13] Gupta, R., Singh, S., Jain, S. and Mandal, A.K. (2006) Recurrent Calcifying Epithelial Odontogenic Tumor of the Maxilla: Report of a Case with Cytologic Diagnosis. Acta Cytologica, 50, 545-547. http://dx.doi.org/10.1159/000326012

[14] Da Rosa, M.R., de Oliveira, J.M., Dias-Ribeiro, E., Ferreira-Rocha, J., de Barros, I.M. and Lopes, P.M. (2011) Large Calcifying Epithelial Odontogenic Tumor with Extension into the Maxillary Sinus: A Case Report. General Dentistry, 59, e38-e40.

[15] Mohtasham, N., Habibi, A., Jafarzadeh, H. and Amirchaghmaghi, M. (2008) Extension of Pindborg Tumor to the Maxillary Sinus: A Case Report. Journal of Oral Pathology \& Medicine, 37, 59-61. http://dx.doi.org/10.1111/j.1600-0714.2007.00567.x

[16] Ferreira, G.J., Alves, K.M., Weege, C.F., Costa, A.M. and Cavalcanti, H. (2009) Calcifying Epithelial Odontogenic Tumor of the Maxilla. Brazilian Journal of Otorhinolaryngology, 75, 468. http://dx.doi.org/10.1590/S1808-86942009000300026 